\title{
JUAN VARELA, DE ADOLFO HERRERA GARCÍA: UN ALEGATO A FAVOR DEL HOMO OECONOMICUS
}

\author{
Irene González Muñoz
}

\begin{abstract}
RESUMEN
Juan Varela, de Adolfo Herrera García, es uno de los textos de la literatura costarricense que ha sido canonizado por la crítica institucionalizada como novela emblemática de la llamada Generación de 1940, pues es el texto que, de acuerdo con esta crítica, determinará la producción literaria posterior, la cual se caracteriza por la denuncia social. El objetivo del presente trabajo consiste, desde una perspectiva crítica de postmodernista, en plantear otros posibles ejes de lectura que pudieron haber determinado que este texto se incluyera dentro del programa escolar costarricense.

Palabras clave: Herrera García-Adolfo, literatura costarricense, novela, Generación de 1940, crítica.
\end{abstract}

\begin{abstract}
In the Costa Rican literature, Juan Varela is a short novel which has been canonized, by the institutional criticism, as the emblematic novel par excellence of the 1940s. The reason, for such consideration, is that according to critics, Juan Varela highly influenced subsequent literary work; whose prime focus was to denounce crucial social issues of that time.

This article aims at establishing, from a postmodern perspective, other reading angles that could have influenced the inclusion of this literary work as mandatory in the Costa Rican school system. Key words: Herrera García-Adolfo, Costa Rican literature, novel, The 40's Generation, critique.
\end{abstract}

Partiendo de la idea de que todo ejercicio de lectura es una actividad que supone, además del reconocimiento de un código, un proceso en el que se pueden construir nuevos significados, lo cual es posible sólo si considera la relación de los textos en cuestión con otros textos y con el conocimiento previo de quien lee, nos proponemos llevar a cabo una (re)lectura de uno de los textos literarios que han sido canonizados dentro del corpus de la producción literaria costarricense, a saber, Juan Varela, escrito por Adolfo Herrera García.

ML. Irene González Muñoz. Profesora del Departamento de Literatura. Escuela de Filología, Lingüística y Literatura. Universidad de Costa Rica.

Correo electrónico: irenego123@hotmail.com

Recepción: 19- 07- 2010

Aceptación: 20- 08- 2010 
Cabe destacar, en primer lugar, que el interés por realizar esta tarea reside en la importancia de revisitar críticamente la novela de Herrera García, la cual durante mucho tiempo fue texto de lectura obligatoria en el sistema escolar nacional, esto por ser considerada como una producción importante dentro del universo cultural costarricense. En este sentido, entonces, la novela se inscribe dentro del corpus de producciones sociales que se incluyeron en el aparato escolar, y tras las que se encuentran una serie de postulados que innegablemente informan; en otras palabras, se nos presentan como una suerte de 'manuales de comportamiento' que establecen o sugieren cómo se debe proceder en determinado orden social, tal podríamos afirmar de aquellas producciones culturales cuya difusión alcanza grandes niveles, como fue el caso del texto en cuestión.

En segundo lugar, otro aspecto por considerar se relaciona con el anteriormente expuesto, pero se trata más de una aclaración, ¿por qué centrar nuestro interés, exclusivamente, en la obra de este autor costarricense? Una respuesta preliminar sería que esta novela de Herrera García, la cual se ha leído siempre como un texto contestatario ${ }^{1}$, cuya publicación se da en un momento socio-histórico de crisis política y económica, paradójicamente, antes que deconstruir el fundamento ideológico de la identidad nacional -sobre el cual se basa a la vez la economía de la nación-, contribuyó con su (re)producción dentro del proyecto del Estado moderno.

En este sentido, nos adscribimos al planteamiento de Jonathan Culler, quien afirma que en los últimos veinte años la teoría literaria lejos de concentrarse en analizar la diferencia entre las obras literarias y las no literarias, se ha centrado más bien en "una reflexión sobre la literatura como categoría social e ideológica, sobre las funciones políticas y sociales que se [cree que realiza] ese algo llamado 'literatura"' (2000: 49). De esta manera, se implica que la literatura es producto de una sociedad histórica y como tal es una producción ideológica que se vincula con ciertas instituciones; por ejemplo, la escuela, lo que le confiere una función socializadora a través de la cual se producen y reproducen determinadas relaciones sociales (Amoretti 1987).

Precisamente, en esta línea de pensamiento, se halla Fernando Aínsa, pensador y crítico uruguayo, autor de Identidad Cultural de Iberoamérica en su Narrativa (1986), quien asevera que en gran medida la narrativa latinoamericana ha contribuido a informar los discursos de identidad, con lo que le confiere a la literatura una marcada función identitaria y nacionalista, al afirmar que la narrativa latinoamericana "ha podido sintetizar la esencia de una cultura y ha [hecho] posible la visión integral de la identidad americana" (1986: 24), incluso con resultados más efectivos que otros discursos, como el histórico, el antropológico o el sociológico.

De acuerdo con Aínsa, entonces, la identidad de América Latina se sintetiza, en buena parte, en sus obras literarias más representativas. Así, las obras de Rómulo Gallegos contribuyen en la representación identitaria de Venezuela y las de Ciro Alegría, con la del Perú, sólo por dar dos ejemplos. De esta manera, se deduce que la identidad cultural de los estados-nación modernos se representa, en gran medida, en aquellas obras literarias que se incluyen en lo que el mismo Aínsa denomina como "parnasos de la cultura oficial, transformándose en parte esencial del sistema nacional que necesita, tanto de héroes, himnos y monumentos, como de una literatura que justifique, sin cuestionarla excesivamente, una cierta idea de la Patria” (1998: 127).

Siguiendo la línea de pensamiento de este autor, un ejemplo concreto de esta función de la narrativa es el caso particular de la construcción de la identidad costarricense, en el cual nos centraremos a continuación, y para desarrollar este tema, consecuentemente con el interés de nuestra propuesta, lo abordaremos a partir de la formación de la narrativa costarricense. 
Para el crítico Álvaro Quesada Soto (1995), la literatura es entendida como una práctica social y también un producto de procesos históricos que determinan su conformación como práctica cultural, así dentro de este marco de referencia propuso que la formación de la literatura nacional costarricense ${ }^{2}$ se conformó en el periodo de 1890 a 1910, etapa en la que se estaba llevando a cabo, a la vez, el proyecto de conformación del estado costarricense, el cual se caracterizó, sobre todo, por los principios del liberalismo, la idealización de las costumbres patriarcales y la crítica de las relaciones mercantiles burguesas (Quesada 1995). Por estas razones, es una literatura altamente marcada por el discurso patriarcal, producto de la concepción de un estado protector fundamentado en la figura paterna (=el Estado), que velaba por el bienestar del pueblo, y este último, por su parte, debía ajustarse a las reformas liberales impulsadas por el Olimpo ${ }^{3}$. Así, la literatura de este periodo construye al personaje que 'encarnará' la identidad del costarricense, pues será el 'representante', la 'esencia' misma del ser costarricense: el concho.

Tal como lo plantea María Amoretti, en Magón...La irresistible Seducción del Discurso (2002), este personaje, el concho, reúne y resume las características ideales de la identidad para un pueblo que debía ser modernizado, pues según lo propone esta autora, se constituye en el modelo sobre el cual se fundamenta no sólo el orden social, sino también todo un proyecto económico.

Según se colige de diversas fuentes, tanto literarias como históricas, este personaje se caracteriza por ser, ante todo, un "labriego sencillo" y trabajador, tal como se afirma en la letra del mismo Himno Nacional ${ }^{4}$, cuyas mejores cualidades son la humildad, la moderación y la autenticidad, todas ellas virtudes asociadas a la ética cristiana, lo cual aseguraba la convivencia pacífica entre los costarricenses y, por lo tanto, aseguraban también que Costa Rica era una buena opción para la inversión del capital extranjero ${ }^{5}$. Al respecto el historiador Carlos Meléndez Chaverri afirma que

\footnotetext{
Diversos viajeros destacan el espíritu pacífico de nuestros campesinos, la honradez que imperaba, al grado de poder confiarles cualquier suma de dinero, el espíritu de cuerpo de los carreteros, que cuando un vehículo sufría algún daño, los demás se detenían hasta que se solucionase la dificultad. (1997: 104)
}

No obstante, estas cualidades positivas, contaba además con algunos antivalores que debían ser combatidos por el discurso liberal: la pobreza, la conformidad y la ignorancia, características que le impedían al país su ingreso en el mundo mercantilizado y que, por lo tanto, debían de modificarse (Amoretti 2002). Para esto, y como parte de un proyecto ideológico tendiente a la conformación de un estado moderno, se genera en el discurso literario de la época, una identidad basada, de acuerdo con Carlos Sandoval (2002), en la figura de un campesino pequeño propietario; es decir, un productor y habitante de una "democracia rural". Así, se construye la identidad "esencialista" del costarricense basada en la imagen de un campesino blanco, trabajador y pacífico, características todas, como ya hemos dicho, que contribuían a la inserción de Costa Rica, como estado moderno, al mercado mundial, en este caso, asociado a la exportación del café. Nótese; sin embargo, que se refiere únicamente al hombre, pues esta construcción margina totalmente a la mujer, y sobre este aspecto nos referiremos más adelante.

Ahora bien, para Giovanna Giglioli (2002) esta identidad del costarricense es una construcción ahistórica e inmutable, pues, por una parte, no responde, de acuerdo con esta autora, a realidades históricas que la fundamenten; es decir, se trata de una invención 
(¿literaria?) que responde más a un proyecto económico que a la 'verdad histórica' (nótese la idea de que la historia es verdadera) y, por otra parte, es inmutable porque surgió en un contexto socio-económico determinado, que ya no se corresponde con el contexto actual, pero la concepción de esa identidad sigue siendo la misma.

Por su parte, Carlos Sandoval, en Otros amenazantes. Los nicaragüenses y la formación de identidades nacionales en Costa Rica (2002), afirma que esta construcción identitaria sí ha sido (re)planteada en diversos momentos del desarrollo socio-histórico del Estado costarricense. En este sentido, afirma que si bien el eje central de esta construcción identitaria fue y es el campesino, en una primera etapa esta figura se relacionó, como ya hemos dicho, con una "democracia rural"; en una segunda etapa, con una "nación de clase media"; y en una tercera etapa, con la "eco-democracia". De esta manera, en la primera etapa, el campesino se perfila como un elemento folclórico, cercano a un personaje idílico del área rural; mientras que en la segunda etapa se trata de un personaje asociado con la zona urbana, pero siempre con características negativas debido a su condición, de esto que reciba la denominación de polo. Finalmente, en la tercera etapa, se le identifica como el guardián de la naturaleza, debido a la importancia que ha tenido la industria turística en los últimos años.

Otro aspecto de esta construcción identitaria se refiere al tratamiento que este personaje, el campesino, ha recibido por parte de diversas prácticas discursivas; pues si bien ha sido el eje fundamental de la identidad nacional, siempre se le ha estigmatizado, al respecto afirma Carlos Sandoval que

\footnotetext{
Esta estigmatización del campesino está profundamente relacionada con los procesos de modernización. De hecho, esta estigmatización no hubiese tenido lugar sin el auge de las relaciones comerciales internacionales y la emergencia de las ciudades y los medios de difusión, los cuales son las condiciones institucionales para la representación de los "polos" como otros "internos". (Sandoval 2002: 136)
}

Entiéndase polo como sinónimo de campesino, ese personaje estigmatizado porque no es lo que debe ser y, que por lo tanto, debe convertirse en un sujeto moderno para calzar en un Estado moderno.

Precisamente, sobre este tema Franz Hinkelammert, en El sujeto y la ley. El retorno del sujeto reprimido (2003), afirma que el sujeto moderno es un constructo de la modernidad que surge a partir de la relación sujeto-objeto, de esta manera el sujeto

\footnotetext{
es visto como instancia que se relaciona con el objeto [...] Como tal es un sujeto del pensamiento, enfrentado al mundo de los objetos. Este sujeto ve toda corporeidad como su objeto, por tanto, también no solamente la corporeidad del otro [...] sino la de su propio cuerpo. Todos los cuerpos, incluyendo el propio, son la res extensa, sobre la cual juzga el sujeto como res cogitans. Eso se lleva hasta la concepción de este yo-sujeto a la instancia (sic.), que hace surgir de su propio yo pensante todo el mundo externo, que puede aparecer como objetivación del pensamiento. (2003: 485)
}

Es decir, Hinkelammert (2003) plantea la existencia de un yo-sujeto, probablemente asociado a los grupos hegemónicos, que no sólo piensa sobre él mismo sino también sobre el otro, al cual a su vez construye. Ahora bien, esta construcción del otro debe responder, en el Estado moderno, a intereses materiales que son siempre intereses particulares calculados; es decir, se persiguen utilidades ya sea para el consumo o para obtener ganancias, así, cuando logra esta construcción del sujeto moderno, estamos ante el ideal de la modernidad: el homo oeconomicus, al que se le exige eficiencia y competitividad, criterios que deben alcanzarse a toda costa, pues así lo requiere el sistema, un sistema en el que todo insumo (incluso el ser humano) debe generar ingresos con tasas máximas, a tal grado que incluso 
Educación y salud se transforman en sectores de creación de capital humano, la distribución de ingresos en incentivación para la aceleración del proceso, la cultura en actividad que da sentido a este sin sentido. (Hinkelammert 2003: 289)

Como vemos, esta postura supone, entonces, la creación de un sujeto moderno productivo y por lo tanto rentable, en el sentido de que su accionar dentro del cuerpo social genere ganancias en todos los sentidos. Finalmente, siguiendo esta misma línea de pensamiento, en su libro Hacia una crítica de la razón mítica. El laberinto de la modernidad, el mismo Hinkelammert se refiere a otra institución que contribuye con esa "creación de capital humano": la ley. Según este filósofo, la ley es un elemento clave para el desarrollo de la modernidad, pues con ella se establecen una serie de exigencias, dentro del sistema de mercado, que deben ser consideradas por el sujeto con la finalidad de que este logre insertarse efectivamente en el sistema (Hinkelammert 2007).

\section{Juan Varela: el despojado}

Según la crítica institucionalizada, la novela Juan Varela, publicada en 1939 y texto emblemático de la literatura costarricense, inaugura un proceso desmitificador de la identidad nacional del costarricense relacionada con lo que Carlos Sandoval denomina la etapa de la "democracia rural". El mismo Sandoval afirma que Juan Varela es producto de una corriente de pensamiento que empezó a cuestionar, en la narrativa nacional, el retrato idílico del campesino (Sandoval 2002).

Así, al hacer una revisión de la crítica hecha a propósito de Juan Varela, encontramos que predomina en toda ella este mismo eje de lectura: se trata, por excelencia, de la novela del despojado.

Sobre este aspecto de la obra en cuestión, Yolanda Oreamuno, en su escrito "Vida y dolores de Juan Varela" (publicado en Repertorio Americano en diciembre de 1939), plantea que este texto debe ser considerado como un hecho emblemático en la literatura nacional pues, aunque Herrera García novela sobre el concho más concho, no lo hace con la intención

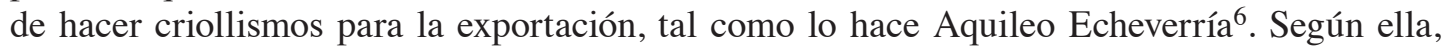
Herrera García nos presenta a Juan Varela, "el concho que ha dejado de ser una comedia que se representa en las escuelas, para convertirse bruscamente en una enojosa y triste realidad" (Oreamuno 1961: 77), realidad que en el caso de esta novela radica en la problemática de la tierra mal repartida o 'muy repartida'. Como vemos, se presenta el texto de Herrera García como un 'reflejo' de la realidad social del campesino costarricense en una época en que los conflictos agrarios en Costa Rica se caracterizan por una problemática socio-económica.

De acuerdo con Abelardo Bonilla (1983), con Vida y Dolores de Juan Varela, publicada en 1939, surge en el panorama de la narrativa costarricense la novela de tema social. Sin embargo, al contrario de Oreamuno, para Bonilla esta es una producción de escasas dimensiones.

Por su parte, Virginia Sandoval de Fonseca, en Resumen de Literatura Costarricense, ubica esta novela dentro de lo que ella denomina "narrativa predominantemente social", porque ya no se trata del campesino pintoresco, sino que presenta "al hombre desposeído de la tierra [...] al par que se desintegra su familia" (Sandoval 1978: 30).Como vemos la lectura de esta autora no difiere en mucho de la hecha por los dos autores antes citados.

Para Jorge Valdeperas (1979), la llamada generación del 40, dentro de la que se clasifica el texto en estudio, surge como resultado de la crisis de la democracia liberal, esto porque con Juan Varela 


\begin{abstract}
se presenta por primera vez en Costa Rica la temática agraria, ya no en relación a las costumbres del campesino o al estado de degeneración de éstas, sino en vinculación directa con las consecuencias sociales del régimen de propiedad de la tierra. Juan Varela aparece como el primer despojado de la literatura costarricense, línea de desarrollo que, excepcionalmente, tendrá un tratamiento posterior en obras como "El sitio de las abras" de Fabián Dobles y algunas otras de menor importancia. (Valdeperas 1979: 49)
\end{abstract}

Como se puede ver, Valdeperas no sólo confirma las lecturas anteriores, sino que también propone esta novela como un paradigma de la producción narrativa posterior, con lo cual le confiere la característica de texto emblemático dentro de la literatura nacional.

En Literatura, Ideología y Crítica (1983), Manuel Picado Gómez realiza una revisión de la crítica hecha sobre la producción narrativa del 40-50, con la finalidad de establecer cuáles han sido los ejes de lectura que conforman este discurso crítico. A partir de su estudio concluye que lo verosímil es uno de los filtros que determinó la forma de leer la producción de este periodo. Ahora bien, lo verosímil se asume a través de las siguientes tres oposiciones binarias:

-lenguaje referencial/lenguaje no referencial

-presencia del autor/ausencia del autor

-naturalidad del texto/artificiosidad del texto

De estas tres oposiciones, la primera es, según Picado, la que determina las lecturas hechas sobre la novela en estudio; es decir, que las lecturas hechas sobre Juan Varela, parten de la idea de que el texto debe servir para algo y debe también dejar constancia de su razón de ser. En otras palabras, Juan Varela es un texto que se adscribe a una producción literaria cuya finalidad es la denuncia, por eso se destaca su carácter referencial, como lo afirma la crítica al aseverar que responde a la crisis de la democracia liberal y a la mala repartición de la tierra, y precisamente por ese valor referencial que se le atribuye es que el texto se inicia con documentos judiciales (Picado 1983), para darle 'credibilidad' a la historia de este campesino.

Finalmente, Margarita Rojas y Flora Ovares (1995) afirman que la producción narrativa de la década de los treinta se caracteriza, ante todo, por la denuncia social y por el alejamiento de la imagen ideal de nación que se construyó en el periodo anterior. Concretamente, sobre Juan Varela refuerzan, a partir de la relación entre Ana y Juan, la idea de que esta se rompe "desde el momento en que el protagonista es despojado de su parcela" (Rojas y Ovares 1995: 128), lo que implica a la vez la pérdida del paraíso que esta pareja había construido en su tierra, la cual pierden, de acuerdo con estas autoras, por causas externas, como la baja de los precios del frijol y de la caña de azúcar, y no por negligencia de Juan. Afirman, además, que

\footnotetext{
A medida que pierde su propiedad, Juan se margina de la ley. Sin embargo, la novela conduce a la idea de que sus delitos no son producto de una maldad propia. Es una realidad exterior a él la que lo empuja a desobedecer la ley. De esta forma, los valores positivos como la entereza, la valentía y la justicia, al encarnarse en Juan, quedan fuera de la ley, mientras que la traición y la injusticia están dentro de ella. El presidio y el fracaso de Juan y Ana son la otra cara, la verdadera, para el autor y los lectores, del universo legal que condiciona la desgracia del campesino. (La cursiva es propia) (Rojas y Ovares 1995: 129)
}

Como vemos, la lectura propuesta por estas autoras introduce un elemento nuevo: la ley, la cual se presenta como la causante del despojo y de la injusticia que sufre el protagonista. Plantean también que se trata de una ley cuyos componentes son la traición y la injusticia, y este es un asunto sobre el que volveremos más adelante.

En síntesis, como se colige de la revisión de la crítica, la lectura general sobre Juan Varela es la del despojado, y gracias a esta interpretación, la novela se clasifica dentro de una producción narrativa cuya intención central es la denuncia social. 
En este punto, resulta pertinente referirnos al hecho de que despojado viene del verbo latino despoliare el cual, a la vez, deriva del sustantivo spolium, cuyo significado es 'piel o despojo', 'pellejo de los animales' (Corominas 2001), por lo cual, etimológicamente despojar significaría, en primera instancia, quitar la piel a los animales; por esto que en el Diccionario de la Lengua Española (2001) se conceptualice despojar como desposeer, con violencia, a alguien de lo que goza. De esta forma, se nos presenta una interrogante: ¿deberíamos asumir, entonces, que Juan Varela es una víctima porque lo que le pertenecía se le arrebató violentamente? ¿Es realmente este el caso?

Además de la lectura del despojado, también se introduce el tema de lo legal en esta novela. Picado Gómez lo considera como un recurso estilístico que brinda verosimilitud al texto, por su parte, Rojas y Ovares establecen un concepto peculiar de la ley que se presenta en esta obra y que retomamos a continuación para proponer nuestra lectura de la novela.

\section{Juan Varela: un alegato a favor de la ley}

En efecto, tal y como lo confirman las críticas anteriormente expuestas, Juan Varela se inicia con un documento legal en el que se le adjudica el terreno baldío en que se asentará con Ana, su compañera:

\footnotetext{
Juan Varela Conejo, mayor, soltero, jornalero, vecino de Santa Bárbara de Heredia, denuncia un lote de terreno baldío, constante de veinte hectáreas, situado en las bajuras de la Barranca, distrito segundo del cantón segundo de la provincia de Alajuela, lindante: al norte, terrenos baldíos; al sur, finca de Angel Quirós; al este, terrenos baldíos; y al oeste, tierras de la sucesión de Santa Ana Barboza. Con treinta días de término cito a los que tengan derechos que alegar a este denuncio que los hagan valer ante esta autoridad. Juzgado Primero de lo Contencioso Administrativo. San José, 29 de enero de 19... (Herrera García 1979: 15)
}

El hecho de que la historia se abra con un documento de este tipo es significativo, no tanto por ser un mero recurso de verosimilitud, como lo asegura Manuel Picado, sino porque desde el incipit se establecen y organizan una serie de códigos que orientan el ejercicio de lectura, en este caso por una relación con la historia que se va a narrar. De esta manera, nos damos cuenta de que Juan es un hombre del pueblo que no tiene las posibilidades económicas para ser terrateniente y, por lo tanto, hecha mano de un recurso legal, reclamar un lote baldío para convertirse en propietario, pues esta es la única manera de convertirse en su propio patrón. Visto de este modo la ley se concibe como el instrumento ideal para la consecución de un bienestar económico y social (al menos esta es la promesa); o sea, Juan se sirve de la ley, vive la ilusión de que la utiliza para su beneficio individual. Así se inicia la historia, Juan y Ana emprenden su viaje desde Santa Bárbara de Heredia hacia las bajuras de la Barranca para establecerse en su tierra:

\footnotetext{
Anochecido ya, refugiáronse en el rancho de unos labriegos, metido definitivamente en las honduras cerreras. Antes de amanecer se oía la correntada del río. Estaban en su tierra. ¡Qué dulzura pensar que era su tierra! La harían fértil, mansa, maternal, abundante, buena. Aquel bosque arisco, aquel silencio avasallador, aquella selva bravía se tornarían en maizales benditos, en frijolares benignos, en cañales rumbosos. (Herrera García 1979: 16-17)
}

Con este tono positivo, el narrador relata la vida idílica con que Juan y Ana sueñan, el cual se hace posible gracias al uso que el protagonista hace de la ley. Sin embargo, esta ley no es más que la ley del valor, la ley del sistema de mercado (Hinkelammert 2007) que someterá a Juan a un accionar determinado, en respuesta a lo que esta ley le concede a él. En otras palabras, Juan no utiliza la ley, sino a la inversa, él es utilizado por esta, de tal forma que 
el protagonista de la novela entra en la "nueva cárcel del cuerpo que es el sistema de mercado" (Hinkelammert 2007: 50), el cual lo obliga a ser productivo para poder no sólo sobrevivir sino también a mantener la tierra, tal como se comprueba en las siguientes citas:

\begin{abstract}
Apenas había tiempo de sembrar el maíz y regar los frijoles [...] Había que hacerlo de prisa. Los ahorros alcanzaban hasta fin de año. Apenas tiempo para recoger la cosecha, venderla y volver a sembrar. (Herrera García 1979: 20)

Y luego a encorvarse sobre la tierra. A desgarrapatear vacas. A ver cómo estaban los yucales. Desyerbar el potrero. A limpiar el yurro. Del trecho de montaña encabritada nada quedaba. (Herrera García 1979: 25)
\end{abstract}

Juan se convierte en el más ferviente agricultor, su tierra y él tienen que ser productivos, de lo contrario su plan fracasará.

Lo interesante es que en efecto Juan y Ana son trabajadores y su finca es muy productiva, pero esto no los salva de perder su tierra. Para Margarita Rojas y Flora Ovares, todo se inicia con la caída de los precios de los productos agrícolas y en este sentido se comprueba cómo estos personajes son víctimas del sistema de mercado. Cuando Juan sale a vender su primera cosecha de frijoles, don Remigio le informa que el precio ha bajado:

-Te lo voy a explicar. Mirá: el año pasado había escasez. Los frijoles subieron a siete cincuenta. A este
precio la gente no podía comprarlos. El gobierno entonces resolvió traerlos de afuera. Con la tríada de
frijoles los precios se vinieron de un sopetón al suelo. ¿Me entendés? (Herrera García 1979: 30)

No obstante esta explicación de don Remigio, Juan no comprende. Él compró semilla a siete cincuenta, por eso debía vender su cosecha a ocho colones la cajuela; además, si había frijoles, ¿por qué razón importarlos? Esta lógica del mercado es incomprensible para él.

A partir de este hecho la bonanza empieza a declinar. Juan empieza a abandonar su trabajo, Ana le reclama su desidia:

\footnotetext{
-Estás como idiota. Fijáte en la milpa. El ternero se murió de puro descuido. Estás desanimado. Vos te desanimas de todo. Sos muy flojo. Aguantemos estos malos tiempos. [...] ¿No has pensado en que tal vez se le saque algo a esa caña? ¡Un trapiche, Juan! Con un trapiche estarías salvado. (Herrera García 1979: 35) (La cursiva es propia)
}

Ana insiste en que su esposo sea productivo (como lo requiere el sistema de mercado en que ingresó), que no sea 'flojo', por esto le sugiere iniciar una nueva empresa, el trapiche; para esto requieren de un préstamo, pues sus ahorros ya se han acabado. Así, Juan decide hipotecar su hacienda por la suma de mil colones. Esta es su segunda transacción directa con la ley y, aunque Ana no está de acuerdo con este nuevo negocio de su esposo, termina accediendo y le dice: “Sea a la mano de Dios!” (Herrera García: 37); es decir, se da un indicio de que Ana ya no tiene confianza en este nuevo trato.

A pesar de la desconfianza de su esposa, Juan firma una hipoteca con el "Banco Americano de Costa Rica" en la que autoriza a su acreedor al remate de la finca en caso de que sea necesario:

[...] manifiesta el compareciente Varela, que, para el caso de ejecución, renuncia su domicilio y los trámites del juicio ejecutivo, dejando autorizado a su acreedor para pedir el remate de la finca hipotecada, con base de la suma por la cual responde; y advertido por mí el señor Varela del valor y trascendencia legales de las renuncias que hace, las aceptó sin objeción. (Herrera García 1979: 37) (La cursiva es propia)

Como vemos, Juan fue advertido de lo que podía suceder, no fue engañado, si no podía saldar su deuda perdería su hacienda y eso es precisamente lo que le sucede. Las últimas palabras de esta cita son definitivas, Juan sabía cuáles eran las condiciones de su gestión financiera y "las aceptó sin objeción". 
¿Cómo podríamos seguir leyendo, entonces, esta novela como la historia del despojado, de aquel contra el que se cometió un abuso, si él personaje había sido advertido de las posibles consecuencias de sus actos? En realidad, Juan pareciera ser sólo víctima de las circunstancias, pues sus negocios no funcionan (¿se insinúa, tal vez, su poca pericia en estos asuntos legales?).

Otro aspecto importante de este segundo trato de Juan con la ley es, precisamente, el hecho de que en esta ocasión sabe lo que está haciendo, vuelve a utilizar (desde su perspectiva) un recurso legal para asegurar su movilidad social y económica; sin embargo, esta vez sí corre el riesgo de perder su tierra, mientras que en la primera sólo obtuvo ganancias, la tierra. Entonces, si la ley lo favorece la primera vez y por medio de ella vuelve a tener otra oportunidad, ¿quién o qué falla, Juan o la ley?

De acuerdo con lo hasta ahora propuesto, pareciera que es Juan quien no sabe 'aprovechar' las oportunidades, pues la ley es la ley y Juan no se ajusta a ella, o como lo proponen Rojas y Ovares, a "medida que pierde su propiedad, Juan se margina de la ley" (1995: 129); o sea, este personaje no opera acorde con la 'lógica' del sistema legal al que se acoge, pues no es competente en este campo y de ahí su fracaso. Pero no es sólo eso, el otro problema es que esta ley a la que Juan se acoge no contempla para nada al ser humano, sino que lo considera en cuanto un sujeto-productor, y al fin ya al cabo, es la ley a la que él se sometió en busca de su progreso personal y familiar.

Finalmente, acudimos a la degradación total de Juan. Una vez que pierde su hacienda, trabaja como peón para otros, pierde este trabajo, y por último instala una saca clandestina por la cual es perseguido por la ley y una noche llegan a arrestarlo:

Elevóse la voz ronca del cabo de fiscales. La misma voz que lleva la desesperanza y la angustia, por las noches, a las casas de los campesinos en revuelta. El resguardo fiscal, disolvedor de mitines obreros, repartidor de cincha en las protestas colectivas, aprehensor de contrabandos... (Herrera García 1979: 62)

Juan mata a dos de los policías que lo llegan a arrestar y luego huye. Regresa para ver a su familia y para matar también a su delator. Luego se entrega por su propia voluntad y es juzgado y condenado a cárcel de por vida. Precisamente, justo después de escuchar la sentencia, pregunta: "-¿Qué quiere decir presidio indeterminado? -Que no precisa, fija ni determina el tiempo que vas a estar preso." (Herrera García 1979: 68). Una vez más se demuestra que Juan Varela parece no entender el lenguaje del discurso judicial porque, en efecto, este no lo contempla a él en su dimensión de ser humano, ya que se trata de una ley del valor de cambio en la que Juan no encaja.

De esta forma, por no ajustarse al sistema legal, Juan pierde no sólo su hacienda y, consecuentemente, su libertad, sino que también pierde a su familia, pues su primogénito muere y Ana se va con otro hombre.

En este punto, es necesario recalcar que la figura femenina, dentro de la novela, si bien no tiene un desarrollo amplio, sí juega un rol significativo dentro de la representación identitaria de 'la costarricense' y, curiosamente, este ha sido obliterado por la crítica.

En el caso de Ana, la esposa de Juan, se puede aseverar que es, al menos al inicio de la historia, la compañera ideal, pues comparte con su esposo el deseo de progreso y de bienestar, se nos presenta así como una mujer laboriosa y abnegada que trabaja al lado de su esposo:

Apenas había tiempo de sembrar el maíz y regar los frijoles. Ana le ayudaba: inclinada sobre el campo iba desparramando puñados de granos, mientras él, más adelante, abría tierra de sembradura entre la montaña tupida. (Herrera 1979: 19)

Aunado a esta imagen, se establece, además, una relación entre ella y la tierra en el sentido de que ambas son fecundas: 
La mañana en que sobre el campo asomaron los primeros tallos del maizal, Ana se echó sobre la tierra. Parecía que le arrimaba, como a una hija, su pecho caliente. En diciembre retoñó Ana. El amor los prolongaba infinitamente sobre los tiempos. (Herrera 1979: 20)

Toda esta construcción idílica que se hace con respecto a Juan y a su esposa en relación con la tierra se ve amenazada, únicamente, según lo hemos planteado, con el fracaso de Juan dentro del sistema legal, lo cual lo expone como un desajustado/marginado dentro de este, y es por esta razón que Ana, finalmente, lo abandona. Un aspecto importante de esta acción de Ana es que no se va con cualquier hombre, se va precisamente con un hombre que dentro del discurso de la identidad costarricense representa una figura externa y amenazante: un nicaragüense (Sandoval 2002). Así termina la historia, cuando Juan, en la cárcel, tiene noticias de su esposa por intervención de su amigo Pedro Pablo Chavarría, quien le dice lo siguiente:

A Ana la vi luego con un nica. Pocos días antes de entortarme me contaron que se iba con el hombre para los bananales de Parrita. Se llevó a la güila y al chiquitito. (Herrera 1979: 74)

Como se ve, se muestra al inicio del texto una figura femenina identificada con la mujer ángel, imagen que se mantiene mientras el universo de Juan marcha bien, pero una vez que se da el fracaso, Ana comete el peor de sus actos: deja al fracasado de su esposo por un nica, con esto la figura positiva que se representa de Ana al inicio de la novela se convierte, al final, en la mujer demonio, lo cual no deja en buena posición a la figura de la mujer campesina, pues su lealtad tarda lo que tardó la buena fortuna de la pareja.

\section{Conclusiones}

Lo anteriormente planteado nos lleva a una primera interrogante: ¿cómo leer este texto dentro de una producción discursiva cuya intención es ser contestataria, si se representa al campesino como un fracasado y a la campesina como una traidora?

Para tratar de responder a esta pregunta y a manera de una conclusión preliminar, un aspecto importante por señalar en nuestra propuesta de (re)lectura de Juan Varela es el hecho de considerar que el fenómeno literario no se considera como un dato empírico sobre el que se puede realizar un análisis que dé cuenta de él. Por el contrario, el fenómeno literario es un constructo teórico que se conforma simultáneamente con el discurso que se refiere a él, entiéndase crítica e historiografía literarias. En este sentido, debemos tener claro que existe una institucionalidad discursiva que determina no sólo qué debemos aceptar o entender por literatura, sino también cómo debe leerse esa literatura.

Desde esta perspectiva Juan Varela es un texto que se incluye, por una parte, como ya hemos visto, dentro del corpus de la literatura costarricense por haber sido leído, por la crítica institucionalizada, como una novela de temática social o más concretamente como la novela del despojado, lo que a su vez permite su clasificación historiográfica dentro de denominada generación del 40. Esto ha hecho posible; además, el establecimiento de un único eje de lectura, el cual ha sido difundido oficialmente por la institución académica, hasta tal punto, que durante mucho tiempo no se ha planteado ningún otro.

Otro aspecto que debe tenerse en cuenta es que esta novela fue de lectura obligatoria dentro del sistema escolar costarricense durante muchos años, a pesar de haber sido 'etiquetado' como un texto contestatario que denuncia las injusticias del sistema establecido. Por esto, resulta interesante considerar otros argumentos empleados para incorporarlo en el aparato escolar. 
A este respecto, Alexánder Sánchez Mora, en "Periodismo y literatura comprometidos. El caso de Adolfo Herrera García” (inédito), establece que la razón de peso para incluir la novela en el programa escolar poco tuvo que ver con que esta denunciará las injusticias del sistema capitalista y sí con la polémica que se generó en 1966 en relación "con uno de los temas políticos más candentes de ese momento: el proyecto de ley, impulsado por la fracción legislativa del gobernante Partido Unificación Nacional, que pretendía la apertura del monopolio estatal sobre los depósitos bancarios”. Así, según lo afirma Sánchez, Juan Varela empezó a leerse, específicamente, como la historia de la víctima de la banca extranjera, lo cual a la vez favorecía el proceso para nacionalizar la banca en Costa Rica.

En lo que concierne a nuestra propuesta de lectura, partimos no de la intención de instaurar el significado último del texto, sino de ofrecer otro sentido, en este caso desde la representación que se hace en la novela del discurso de la ley, que nos permita proponer otra razón posible para que el texto se incluyera en el programa escolar.

De acuerdo con la lectura que establece la crítica, Juan es víctima de la injusticia de la ley; sin embargo, esta propuesta se puede cuestionar, sobre todo, si consideramos que Juan se sirve de ella para asegurarse su progreso individual, y de hecho le sirve pues puede convertirse en propietario ejerciendo su derecho al denunciar un terreno baldío ${ }^{7}$, lo que sucede es que Juan no conoce cuáles son las reglas del sistema en el que entró. Lo mismo le sucede en la segunda oportunidad al hipotecar su propiedad con la idea de construir el trapiche, pero una vez más Juan no se ajusta las reglas. Incluso, en el texto, se aclara que él comprendía cuáles eran las condiciones de la hipoteca y por esto firma el contrato.

En relación con el tema del contrato, Alberto Brenes Córdoba afirma, en Tratado de los Contratos (1985), que este es un mecanismo esencial del derecho, cuyo origen se sitúa en la sociedad liberal, en este sentido, tanto en su constitución como en sus efectos deben considerarse cuatro principios básicos de la ideología liberal. El primero de ellos es el principio moral de la autonomía de la voluntad, el cual se refiere a la voluntad del individuo de someterse a la ley de los hombres, que es precisamente lo que hace Juan al acogerse, en ambas oportunidades, a una ley de la cual se sirve para sus fines personales. El segundo es el principio económico de "dejar hacer", este se encuentra estrechamente relacionado con el primero, pues plantea que "dejando actuar a las voluntades humanas [...] se obtiene el mejor resultado económico" (Brenes Córdoba 1985: 14); es decir, que tanto Juan como las otras partes con las que él establece contratos están en su derecho de que sus inversiones generen ganancias máximas. El tercer principio es el individualismo, el cual supone que el individuo sea no solo su propio dueño, sino también capaz de decidir por sí mismo, tal y como lo hace el protagonista de esta historia, pues nadie lo fuerza a hacer nada. Finalmente, el cuarto principio es el más característico y esclarecedor, se fundamenta en que

\footnotetext{
La ideología liberal clásica no se preocupa de manera alguna de las desigualdades físicas, culturales y económicas de los individuos. La igualdad de los de los individuos es una igualdad abstracta, que supone que todas las personas tienen igual aptitud para ejercer una actividad conforme a su voluntad. (Brenes Córdoba 1985: 16) (La cursiva es propia)
}

De acuerdo con este cuarto principio, entonces, Juan no entra en un sistema legal que considere sus carencias, todo lo contrario, entra en igualdad de condiciones con respecto a las otras partes. De esta manera, se comprueba que no se trata de que esta ley sea traidora e injusta, según lo plantea la crítica revisada, pues como ya hemos afirmado, se trata de un instrumento para la movilidad socioeconómica del protagonista; o sea, se trata de una ley que responde a uno de los mitos de la modernidad: el progreso del ser humano. 
El fracaso del protagonista reside en que él desconoce cómo funciona ese sistema legal que en principio le promete progreso, pues no se trata de la ley arcaica, sino más bien de una ley que se presenta como un marco categorial, una ley sobre la que no se discute, solo se debe conocerla y aceptarla tal y como se propone, y el problema de Juan es que la desconoce. En otras palabras, más que despojado, Juan es un desajustado (¿fracasado?) del sistema, no responde como el homo oeconomicus debido a su desconocimiento de ese sistema legal que le prometía movilidad económica y social. Por eso lo pierde todo, incluso a su mujer y a sus hijos, y por eso termina siendo un marginado, pues, en términos de Kant (2004) ${ }^{8}$, Juan es un ser humano que no ha alcanzado su mayoría de edad, pues no puede servirse de su entendimiento, debido a que no goza de la instrucción requerida para calzar en el sistema y, de esto, su fracaso.

Finalmente, a partir de esta lectura, cabe preguntarse entonces: ¿representa Juan un modelo que debe ser imitado o un modelo que debe ser evitado? Probablemente en la respuesta se encuentre la razón para que este texto se incluyera, durante mucho tiempo, en el sistema escolar costarricense.

\section{Notas}

1. Esta ha sido la lectura que la crítica académica ha institucionalizado sobre este texto.

2. Nos referimos al corpus de obras que los grupos de poder y la Academia institucionalizan como literatura nacional durante el periodo 1890-1910.

3. Se refiere a la élite de intelectuales y políticos de la oligarquía cafetalera que impulsó, hacia 1989, las reformas liberales en el país.

4. Para esto, ver el es estudio de María Amoretti, Debajo del canto: un análisis del Himno Nacional de Costa Rica. 1987. San José: Editorial de la Universidad de Costa Rica.

5. Sobre este tema se han referido varios estudiosos costarricenses como Iván Molina y Tatiana Lobo, además de los citados en este trabajo.

6. Quien construye o moldea al concho del costumbrismo como una figura risueña, a pesar de su tragedia personal.

7. En este sentido, Rodrigo Barahona Israel, en su artículo “La propiedad agraria”, en el que se refiere, entre otros aspectos, a la regulación de la propiedad agraria en Costa Rica, expone cómo en 1934 debido a la creciente desocupación en el sector agrario, se firmó la Ley de Cabezas de Familia, la cual otorgaba a aquellos que no poseían tierra el derecho a denunciar terrenos baldíos.

8. Propuestas desarrolladas por Inmanuel Kant en respuesta a la pregunta, ¿qué es la ilustración?, planteada por el párroco berlinés J. F. Zöllner, en 1783, en la revista Berlinschen Monatsschrift.

\section{Bibliografía}

Aínsa, Fernando. 1986. Identidad cultural de Iberoamérica en su narrativa. Madrid: Editorial Gredos.

1998. "Problemática de la identidad en el discurso narrativo latinoamericano". En: Fronteras e identidades. San José: Editorial de la Universidad de Costa Rica. 
Amoretti Hurtado, María. 2002. Magón... La irresistible seducción del discurso. San José: Ediciones Perro Azul.

Barahona Israel, Rodrigo. 1991. "La propiedad agraria”. En: Antología. Cátedra de Derecho Agrario. Facultad de Derecho, 147-163. San José: Universidad de Costa Rica.

Bonilla Baldares, Abelardo. 1981. Historia de la Literatura Costarricense. San José: Editorial STVDIUM.

Brenes Córdoba, Alberto. 1985. Tratado de los contratos. San José: Editorial Juricentro.

Corominas, Joan. y José A. Pascual. 2001. Diccionario crítico etimológico castellano e hispánico. Vol. II. Madrid: Editorial Gredos.

Diccionario de la Real Academia Española. 1992. Tomo II. España: Talleres Gráficos Peñalosa, S. A.

Foucault, Michel. 2005. Las palabras y las cosas. Una arqueología de las ciencias humanas. Buenos Aires: Siglo XXI Editores.

Giglioli, Giovanna. 2002. "Los colores de la idiosincrasia". En: Identidades y ciudades. Patrimonios imaginarios. San José: Editorial Arlekín.

Herrera García, Adolfo.1979. Juan Varela. San José: Editorial Costa Rica.

Hinkelammert, Franz. 2003. El sujeto y la ley .El retorno del sujeto reprimido. San José:Editorial EUNA.

Hinkelammert, Franz. 2007. Hacia una Crítica de la razón mítica. El laberinto de la modernidad. San José: Editorial Arlekín.

Kant, Inmanuel. 2004. ¿Qué es la Ilustración? Y otros escritos de ética, política y filosofía de la historia. Madrid: Alianza Editorial.

Meléndez Chaverri, Carlos. 1997. Historia de Costa Rica. San José: Editorial EUNED.

Rojas, Margarita y Ovares, Flora. 1995. 100 Años de Literatura Costarricense. San José: Ediciones Farben.

Oreamuno, Yolanda. 1961. A lo Largo del Corto Camino. San José: Editorial Costa Rica.

Picado Gómez, Manuel. 1983. Literatura/Ideología/Crítica. Notas para un estudio de la literatura costarricense. San José: Editorial Costa Rica. 
Quesada, Alvaro. 1995. La formación de la narrativa nacional costarricense. Enfoque histórico social. San José: Editorial de la Universidad de Costa Rica.

Sánchez Mora, Alexánder. Inédito. "Periodismo y literatura comprometidos. El caso de Adolfo Herrera García”.

Sandoval García, Carlos. 2002. Otros amenazantes. Los nicaragüenses y la formación de identidades nacionales en Costa Rica. San José: Editorial de la Universidad de Costa Rica.

Sandoval de Fonseca, Virginia. 1978. Resumen de Literatura Costarricense. San José: Editorial Costa Rica.

Valdeperas, Jorge. 1979. Para una Nueva Interpretación de la Literatura Costarricense. San José: Editorial Costa Rica. 